\title{
CHARLES BAUDELAIRE E O ESPIRITUAL NAS ARTES: UM ESTUDO COMPARATIVO ENTRE POESIA E PINTURA MODERNA
}

\section{CHARLES BAUDELAIRE AND THE SPIRITUAL IN THE ARTS: A COMPARATIVE STUDY BETUEEN POETRY AND MODERN PAINTING}

\author{
Acuinaldo José Gonçalves* \\ Giularde de Abreu Narvaes"
}

Resumo: Não há como atravessar verticalmente a obra poética de Charles Baudelaire sem considerar em algum momento, e espera-se que não tarde, a persistência das correspondências poéticas. Neste trabalho, por meio de uma análise intersemiótica dos sistemas de linguagem, destacamos correspondências estruturais entre dois sonetos de Les fleurs du mal e a modernidade plástica das obras de Wassily Kandinsky e Jackson Pollock. Aspecto fulcral e determinante às leituras comparadas que apresentaremos, a teoria das correspondências na poesia de Baudelaire torna-se assunto incontornável para qualquer abordagem comparatista entre sua poesia e as obras plásticas da modernidade.

Palavras-chave: Baudelaire, intersemiótica, correspondência, artes, modernidade

Abstract: There is no way to traverse the poetic work of Charles Baudelaire without considering at any moment, and is expected not to be late, the persistence of poetic correspondences. In this work, through an intersemiotic analysis of language systems, we highlight structural correspondences between two sonnets of Les fleurs du mal and the plastic modernity of the works of Wassily Kandinsky and Jackson Pollock. A central and determining aspect to the comparative readings we will present, the theory of correspondences in Baudelaire's poetry becomes an inescapable subject for any comparative approach between his poetry and the plastic works of modernity.

Keywords: Baudelaire, intersemiotic, correspondence, arts, modernity

\footnotetext{
* Doutor pela Universidade de São Paulo (USP) e livre-docente pela Universidade Estadual Paulista (Unesp).

${ }^{* *}$ Doutorando em Letras pela Universidade Estadual Paulista (Unesp).
} 
onsiderado um dos maiores expoentes da poesia moderna em todo o mundo, Charles Baudelaire realizou em seus versos, principalmente aqueles que figuram a coletânea Tableaux parisiense, uma visão ao mesmo tempo insólita, bela e fluida das paisagens naturais, que, à revelia dos modelos clássicos, tornaram-se experiências íntimas de contemplação, sempre moduladas pelos artifícios próprios da linguagem poética. Trata-se de imersões no imaginário, um mundo de símbolos familiares sobre o qual se eleva o espírito sensível do poeta imbuído dos traços mais frementes de seu tempo.

Sua consciência social e histórica, seu estilo e verve poética, levaram Baudelaire a uma necessária busca por uma expressão que se fizesse no imaginário. Tal "concepção de imaginação criadora" é desenvolvida no ensaio Le gouvernement de l'imagination, presente no Salon de 1859, e traz reflexões que aprofundam princípios poéticos também encontrados em alguns de seus pares, como Edgar Allan Poe, Samuel Taylor Coleridge, Novalis, Gérard de Nerval e Friedrich Schiller. Realizando fundamentais ampliações dos significantes verbais, Charles Baudelaire não se torna apenas o principal antecipador de relevantes vertentes artísticas da Modernidade, mas um curioso e estimulante referencial para a compreensão das correspondências, não apenas temáticas, mas essencialmente estruturais, entre as artes e seus diferentes sistemas de linguagem.

Em suas reflexões como crítico de arte, Baudelaire mostrou-se frequentemente confrontado com relações analógicas superficiais entre a poesia e a pintura, ganhando mais sua atenção aquelas entre as obras plásticas de Eugène Delacroix, muito admiradas pelo poeta, e a poesia de Victor Hugo, que resultaram, por sua vez, em graves equívocos conceituais.

Não há como atravessar verticalmente a obra poética de Baudelaire sem considerar em algum momento, e espera-se que não tarde, a persistência das correspondências poéticas. Aspecto fulcral e determinante às leituras comparadas que apresentaremos neste trabalho, a teoria das correspondências na poesia de Baudelaire torna-se assunto incontornável para qualquer abordagem comparatista entre sua poesia e as artes plásticas. Em Richard Wagner et Tannhäuser à Paris, Baudelaire é judicioso a esse respeito:

c'est que le son ne pût suggérer la couleur, que les couleurs ne pussent pas donner l'idée d'une mélodie, et que le son et la couleur fussent impropres à traduire des idées; les choses s'étant toujours exprimées par une analogie reciproque, depuis 
le jour où Dieu a proféré le monde comme une complexe et indivisible totalité. (BAUDELAIRE, 2012, p. 75)

Imediata e necessária lembrança, assim como se sucedeu nesse famoso artigo de Baudelaire, trazemos aos olhos do leitor o soneto IV - Correspondances,, presente na primeira parte de Les fleurs du Mal, e sobre ele tecemos, em seguida, breves comentários:

La Nature est un temple où de vivants piliers

Laissent parfois sortir de confuses paroles;

L'homme y passe à travers des forêts de symboles

Qui l'observent avec des regards familiers.

Comme de longs échos qui de loin se confondent

Dans une ténébreuse et profonde unité,

Vaste comme la nuit et comme la clarté,

Les parfums, les couleurs et les sons se répondent.

II est des parfums frais comme des chairs d'enfants,

Doux comme les hautbois, verts comme les prairies,

- Et d'autres, corrompus, riches et triomphants,

Ayant l'expansion des choses infinies,

Comme l'ambre, le musc, le benjoin et l'encens,

Qui chantent les transports de l'esprit et des sens. (ibid., p. 138)

Atrelado às reflexões de Baudelaire em ocasião da ópera de Wagner, Correspondances estabelece de imediato, em seu primeiro verso, um símile inolvidável, um axioma poético vital ao desenvolvimento das imagens subsequentes. Sua compreensão, todavia, não se faz tão imediata quando parece pretender sua simplicidade verbal. A "Natureza”, na poesia de Baudelaire, torna-se espaço consagrado à exaltação do espírito e dos sentidos, templo de meditação e de mediação, elo entre o insondável infinito extrassensível e o finito corruptível das coisas sensíveis do mundo físico. Este espaço natural transfigura-se sob a espessura de floresta de símbolos, misterioso entreposto através do qual cami- 
nha o homem, que percebe figurar-se diante de si uma unidade etérea e fugidia, formada por espécies fractais de significação, originadas da experiência sensível do mundo em alto grau de subjetividade e modulação. Estes fractais poéticos, compostos de símiles e metáforas, resultam de procedimentos de uma simetria estrutural entre os macro e micro elementos da composição, plasmando em suas qualidades verbais, sonoras e semânticas, a representação sensível de uma totalidade extrassensível. Sua "tenebrosa e profunda unidade" encontra-se somente revelada quando alçado o olhar ao nível das sensíveis correspondências, por meio das quais os troncos das árvores de um bosque tornam-se símiles dos pilares de um templo, preenchendo de "anima" a natureza inanimada da pedra esculpida (vivantes piliers); ou o ar movente, impulsionado por fonemas sibilantes que, amalgamados a assonâncias difusas, atravessam o verso (Laissent parfois s sortir de confuses paroles;), assemelhando-se a confusos sussurros, vozes e frases, que provocam símiles sonoros entre vocábulos de sentidos similares, por sua vez curiosamente aparecendo dispostos em igual distância em relação ao centro dos versos (notemos os distanciamentos simétricos entre os vocábulos longs e loin, une e unité, unité e clarté, nos dois quartetos do poema).

Com o intento de demonstrar, partindo das correspondances verbo-visuais, relações estruturais entre a poesia de Baudelaire e algumas obras plásticas pinçadas da vertente abstrata da pintura moderna, objetivamos antes, começar a pensar a modernidade poética do escritor francês ainda sob uma mais antiga e essencial teoria estética, a teoria do símbolo artístico.

Um de seus principais teóricos e personalidade decisiva na formação do pensamento neoclássico europeu, Johan Joachim Winckelmann (1717-1768), arqueólogo alemão e estudioso da Antiguidade clássica, buscou pensar o símbolo artístico a partir da redescoberta estética de esculturas e pinturas de divindades pagãs, criadas por artistas gregos a partir de modelos humanos. Observando que tal fato não representaria qualquer irregularidade nas grandes leis universais da arte, Winckelmann observa que "a beleza sensível proporcionou ao artista a formosa natureza; [e] a beleza ideal lhe proporcionou os traços sublimes. Daquela, tomou o humano, desta o divino" (apud GONÇALVES, 1994, p. 57). Para Walter Benjamin, Winckelmann, em suas reflexões fortemente influenciadas pelos ideais neoclássicos, acaba por tomar o símbolo artístico como símbolo plástico, e deste modo, aproxima-se um pouco mais, em relação a seus pares, de um olhar mais preocupado com a natureza puramente estética das obras es- 
cultóricas gregas. Nestas, o arqueólogo vê uma fusão entre o inefável do místico (extrassensível), de caráter infinito e eterno, e a finitude da natureza (cf. GONÇALVES, 1994, p. 57 ). Segundo Benjamin, por meio de tal visão "a contradição entre o infinito e o finito se dissolve, porque o primeiro, autolimitando-se, se humaniza." (apud ibid., p. 57).

Há no poema Correspondances, contudo, uma inversão ontológica de tal teoria setecentista do símbolo artístico proposta por Winckelmann, articulando a proposição de uma nova acepção para o signo poético, em que a alegoria parece se firmar como batuta a dirigir todas as relações imagéticas. O homem, que agora atravessa uma floresta íntima de símbolos familiares, não experimenta mais a visão transubstanciada da plenitude divina, como procurava alcançar o classicismo com suas miragens plásticas e simbólicas. Pelo contrário, enquanto ser vivente, o homem encontra-se envolto por uma natureza de transitoriedades, "campos de ruínas" e "depósitos de ossos", para lembrarmos as considerações de Benjamin, espaço impossível à vida eterna, pois inevitável abismo de declínio e morte. E na consciência desta realidade existencial que atua o poeta, esforçado alquimista a tomar os significantes de uma linguagem tradutora do mundo sensível e os expandir para além do imitatio de uma Natureza triunfante, racionalmente engendrada sob as formas claras e distintas do pensamento sublimado. Este pensamento, incapaz de estabelecer correspondências com a irrefutável natureza decadente dos objetos sensíveis, veemente recusa não apenas o mundo exterior, mas a própria natureza decadente do homem.

Os significantes poéticos em Baudelaire assumem a busca consciente por uma expressão sincera do espírito, apresentando um imaginário do ideal composto não mais por símbolos de plenitude, mas por alegorias morais advindas de um mundo decaído, que como oceano, faz-se reflexo inconstante do céu; e como matéria, é fragmento e ruína do infinito. Parfums frais, chairs d'enfants, les hautbois, les prairies, tornam-se fractais de uma experiência transfigurada no espírito, instância na qual se realiza a unidade perdida da Natureza, cuja Beleza não mais emana de objetos sensíveis harmonicamente lapidados, mas de um mundo imaginado, produzido pelas correspondências dos sentidos. Tomando, por fim, os dois tercetos que encerram Correspondances, notamos uma fluida composição de símiles (Parfums frais comme des chairs d'enfants, Doux comme les hautbois, verts comme les prairies), estes enredados pelo solfejo de fonemas fricativos chiantes (/f/ e /ch/) e fonemas nasalizadas (/m/ e /n/), responsáveis por 
produzir, sob o nível sintático-verbal do poema, a musicalidade ${ }^{1}$ meditativa de um coro de vozes ciciantes, integrantes essenciais de um espaço consagrado à elevação da mente e à contemplação das sensações de um mundo unificado no espírito. Sob um templo exótico, purificado por substâncias orientais (l'ambre, le musc, le benjoin et l'encens), que parecem metaforizar a própria ação moduladora dos significantes poéticos, o homem encontra-se, por fim, em estado pleno de êxtase, enlevado por uma natureza imanente, que transfigurada no homem, através dele se unifica, fazendo-se transports de l'esprit et des sens. Segundo o espiritualista sueco Emanuel Swedenborg (1688-1772), "telle est l'efficacité du symbolisme qu'il nous console de quitter la Terra, en la présentant comme un aperçu du Ciel, mais qu'il nous donne aussi de la puissance pour cette vie, en nous conduisant à la magie, à l'utilisation du surnaturel" (BAUDELAIRE, 2012, p. 78).

Correspondanses torna-se, então, libelo poético contra a mais autêntica arte neoclássica, ou toda estética que ainda insista na ilusão do imitatio, confundindo as formas exatas e sublimes da imagem artística com a visão idealista de uma realidade jamais contemplada em seus fragmentos de ruínas e de decadência. $A$ poesia de Baudelaire impõe-se como moderna na medida em que percebemos, em razão dos símiles, metáforas e a sonoridade ressonante empregada na composição, a diluição dos objetos sensíveis e referenciais das escolhas temáticas empreendidas, transfigurando-os em fractais de sensibilidade que ressoam no espírito, e restituem, deste modo, por meio das correspondências que estabelecem entre si, a condição edênica a um mundo interior em complexa e indivisível totalidade.

Percebemos, assim, a poesia de Baudelaire encontrar-se em profunda relação com o abstracionismo de Wassily Kandinsky (1866-1944). Para o pintor e teórico russo, a cor, assim como a música, era uma força poderosa capaz de influenciar diretamente a alma e nela provocar sensações.

\footnotetext{
${ }_{1}^{1}$ Para Baudelaire, “La musique donne l'idée de l'espace. Tous les arts plus au moins, puisqu'ils sont nombre et que le nombre est une traduction de l'espace" (BAUDELAIRE, 2012, p. 78). Como procuraremos demonstrar ao longo deste trabalho, a poesia de Baudelaire, não apenas deveu à musica e principalmente à pintura de sua época suas influências, mas deixou, por meio dos invariantes fractais poéticos de sua linguagem, relações substanciosas com a música, a poesia e as artes plásticas modernas.
} 
Em 1895, 28 anos após a morte de Baudelaire, Kandinsky, próximo de completar 30 anos, vivencia dois momentos que iriam mudar radicalmente sua vida. O primeiro viria com o grande desânimo sentido ao contemplar um quadro de Claude Monet, à época da mostra dos impressionistas em Moscou. Segundo Kandinsky,

de repente, estava pela primeira vez diante de uma pintura que representava um palheiro, como dizia o catálogo, mas que eu não a reconhecia como tal. Essa incompreensão me perturbava e aborrecia [...]. A pintura parecia dotada de uma força fabulosa, mas inconscientemente o 'objeto' tema da obra perdia para mim parte de sua importância como elemento indispensável. (KANDINSKY, 2011, p. 13)

Nesta mesma época, ao ouvir Lohengrin, de Richard Wagner, e vendo-se tomado por uma tormentosa imagem do pôr do sol sobre os telhados de Moscou, Kandinsky revela: "parecia ver todas as minhas cores, estavam debaixo dos meus olhos. Linhas desordenadas, quase extravagantes desenhavam-se diante de mim." (ibid., p. 13).

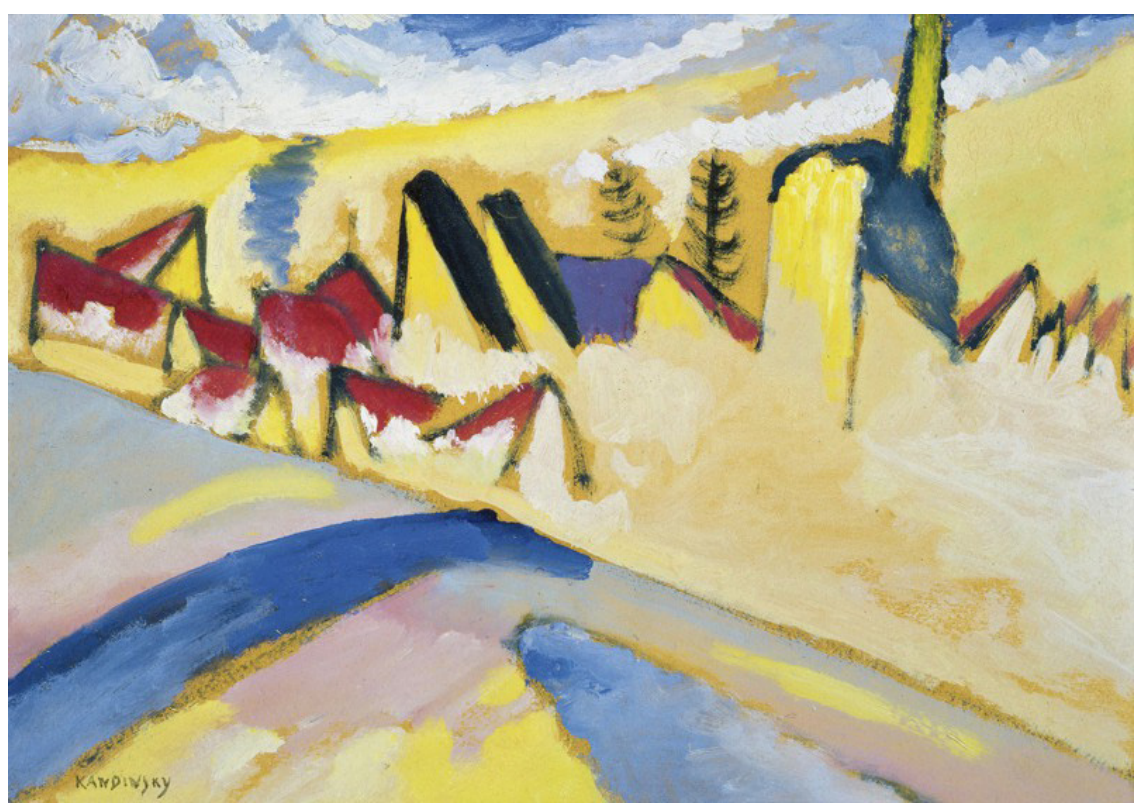

Fig. 1 
Em 1910, Kandinsky compõe Estudo para Inverno /l (fig. 1). O quadro insere-se em uma fase de sua obra marcada pela consciente "dissociação do figurativo", em que as bases da abstração encontram-se plenamente fundamentadas em sua poética visual. Mesmo ainda trazendo alguns componentes figurais reconhecíveis no interior da moldura, neste Estudo, o pintor russo realiza, sobre a superfície bidimensional da tela, uma curiosa partitura cromática, cujos acordes mostram-se vigorosos. Um grande acorde amarelo, com matizes de distintas luminosidades, ressoa em toda a dimensão da tela, na qual observamos objetos figurais diluírem-se como que absorvidos por uma substância fluida. Sobre esse fundo luminoso e movente, realizando-se como um "baixo contínuo" musical, surgem, contrapondo-se, vibrantes tonalidades de azul e de vermelho.

Notamos, na obra de Kandinsky, um processo de "poetização plástica do tema", em que a paisagem hibernal adquire, conforme propôs o pintor russo em sua teoria estética, ${ }^{2}$ as nuanças próprias da metáfora musical, que, enquanto medium de reflexão, para lembrarmos Walter Benjamin, garantem as relações espirituais necessárias à pintura. Poderíamos, em um breve exercício do olhar, contemplar a tela de Kandinsky iniciando um movimento da esquerda para a direita. Veríamos, deste modo, uma nascente concentração de amarelo, pontuada por pequenas e intensas manchas vermelhas, que perdem a intensidade à medida que o azul cresce, chegando ao meio do quadro onde o preto atravessa verticalmente a paisagem, transferindo ao fundo o azul e o vermelho, agora menos vibrantes, enquanto o amarelo se avoluma, impregnado do branco, sob uma larga diagonal disfórica, matizando-se, por fim, dos tons terrosos de uma anterior textura outonal. $\mathrm{O}$ quadro também pode ser lido de baixo para cima, em que se impõem mais potentes as dinâmicas manchas circulares e os geometrismos agudos que atribuem maior intensidade às notas cromáticas.

Assim verificamos possibilidades distintas de significação para os diferentes movimentos que a composição plástica de Kandinsky executa. Segundo Paul Klee (1879-1940), pintor suíço e idealizador do movimento Bauhaus, todo "vir a ser" da obra de arte repousa em um movimento (cf. KLEE, 1979, p. 59). Para o ensaísta, o significante espacial também é uma noção temporal. A pintura, assim como o poema e a execução musical, monta-se peça por peça, assim como o es-

2 "A beleza da cor e da forma não é meta suficiente para a arte", afirma Kandinsky (1995, p. 19). 
pectador necessita mais do que um rápido olhar sobre um objeto estético para começar, a partir daí, a interpretar seu sistema de linguagem.

Após apresentarmos, nesse primeiro movimento de análise, algumas relações estruturais entre o poema IV-Correspondances, de Baudelaire, e a obra Estudo para Inverno II, de Wassily Kandinsky, voltamos, para este segundo movimento, novamente à obra poética do escritor francês, objeto central deste estudo, e fonte ética e estética a encetar as próximas reflexões.

Paul Valéry, ao observar o fecundo legado de Charles Baudelaire à poesia moderna, dizia tratar-se de um poeta "à qui nous devons ce retour de notre poésie vers son essence, et aussi l'un des premiers écrivains français qui se soient passionnément intéressés à la musique proprement dire." (apud BAUDELAIRE, 2012, p. 88). Precursor das primeiras reflexões sobre a modernidade, e atento observador de suas manifestações na sociedade e nas artes de seu tempo, Baudelaire soube conciliar em sua criação poética as marcas de uma formação romântica e de um pensamento clássico. Sua linguagem sóbria e meditada, concisa, límpida e sem volteios, o fez um poeta alheio aos devaneios e volúpias de um romantismo sentimental, como um Alfred de Musset ou um Alphonse de Lamartine, mostrando-se, porém, incapaz de ignorar as alegorias barrocas que atravessavam, numa espécie de diagonal tensiva, as mais importantes obras de William Shakespeare, Dante Alighieri, Lord Byron ou de Ludovico Ariosto.

Sensitiva, sem jamais entregar-se ao ardor sentimental; voluptuosa, sem profanar-se sob a lascívia de um bordeleiro, a poesia de Baudelaire compõe-se de versos austeros e ritmados por uma sinuosidade sempre tensiva, trazendo uma racional religiosidade às formas etéreas do mundo e da arte. Tais aspectos encontramos sintetizados nos vaporosos versos de Brumes et pluies, cujas estrofes transcrevemos a seguir:

Ô fins d'automne, hivers, printemps trempés de boue,

Endormeuses saisons! je vous aime et vous loue

D'envelopper ainsi mon coeur et mon cerveau

D'un linceul vaporeux et d'un vague tombeau.

Dans cette grande plaine où l'autan froid se joue,

Où par les longues nuits la girouette s'enroue,

Mon âme mieux qu'au temps du tiède renouveau 
Ouvrira largement ses ailes de corbeau.

Rien n'est plus doux au coeur plein de choses funèbres, Et sur qui dès longtemps descendent les frimas, Ô blafardes saisons, reines de nos climats,

Que l'aspect permanent de vos pâles ténèbres,

- Si ce n'est, par un soir sans lune, deux à deux,

D'endormir la douleur sur un lit hasardeux. (ibid., p. 350)

Estrofes como essas nos trazem a imediata lembrança de Valéry, ao dizer:

Il y a dans les meilleurs vers de Baudelaire une combinaison de chair et d'esprit, un mélange de solennité, de chaleur et d'amertume, d'éternité et d'intimité, une aliance rarissime de la volonté avec I'harmonie, qui les distinguent nettemente des vers romantiques comme ils les distinguent nettemente des vers parnassiens. (ibid., p. 90)

Dos parnasianos, Baudelaire nega o ideal de "arte pela arte", repudiando os determinantes formais do Belo perfeitamente fingido, e renegando uma poética aduladora dos vernáculos esmerilados. Em Les fleurs du mal, em sentido diametralmente oposto à tradição clássica, nasce uma espiritualidade poética que só a modernidade virá vicejar. Com Baudelaire, a poesia retorna ao ofício ancestral de expressão através do imaginário, das figurações mais recônditas da condição humana. "O que é a arte pura segundo a concepção moderna? É criar uma magia sugestiva contendo ao mesmo tempo o objeto e o sujeito, o mundo exterior ao artista e o próprio artista.", observa Baudelaire em L'art romantique. A poesia volta a ser, como na poesia latina de Catulo, na metafísica poética proposta por Giambattista Vico, ou no teatro de Racine, a manifestação de uma beleza sagrada, originada dos êxtases e das agonias da alma, uma alma descarnada, filha da tensão e da disjunção das emoções unificadas de maneira tensa no interior de sua poesia. Daí o caráter a um tempo "divino e infernal da beleza." (ibid., p. 92).

Em Brumes et plueis, poema presente na seção Tableaux parisiens, de Les fleurs du mal, a forma clássica e o espírito moderno mais uma vez se confundem em um trabalho excepcional de versificação. Realizando-se sob uma rigorosa 
estrutura formal, o tema de uma paisagem chuvosa de fim de outono plasma-se sob um melancólico ritmo ternário de versos alexandrinos, compondo uma partitura vaporosa e arrefecida, cujas notas/rimas pouco sonoras, parecem aproximar a tessitura verbal à gravidade de um lânguido cantochão medieval. Notamos nos quartetos as rimas paralelas realizarem-se em boue/loue, cerveau/tombeau, joue/s'enroue, renouveau/corbeau, entoando uma sonoridade de certo modo próxima ao imaginário romântico, mas em Baudelaire certamente mais comovida pela dicção soturna de um Edgar Allan Poe. Baudelaire metaforiza a paisagem outonal, compondo, na linha rítmica ternária dos versos, um movimento sincopado por aliteração oclusivas em / $t$ / e / $d /$, que parecem aludir à austera queda de uma melancólica chuva, imagem esta reforçada pela dissonante permanência de fonemas fricativos na primeira $(/ v /)$ e na terceira $(/ f /)$ estrofes. Ligadas à sonoridade monódica das consoantes nasais, a camada lexical e semântica dos versos parece diluir os componentes figurais do tema, pondo sobre tais imagens sensíveis uma translúcida camada de névoa, também aludida pelas aliterações que possuem pontos culminantes de dissonância no fim da segunda e quarta estrofes.

Brumes et plueis é exemplar triunfo do spleen sob o espírito criador do poeta. Faz da palavra precisa expressão de formas vagas e confusas, cujos paradoxais componentes verbo-figurais (como printemps trempés de boue ou l'autan froid) ${ }^{3}$ realizam, assim como os componentes plásticos-figurais na pintura de Kandinsky, a desreferencialização e diluição dos próprios constituintes figurais, que parecem desfocar-se a todo instante como que atravessados por um véu funéreo agitado pelas sensações tenebrosas de um coração enlutado. Assim como em Correspondances, há neste quadro outonal um espaço contemplativo e de louvação, onde o espírito, por meio de um imaginário constituído de expressivas metáforas e agudas sinestesias (como em D'un linceul vaporeux et d'un vague tombeau ou Dans cette grande plaine où l'autan froid se joue), aparta-se do mundo sensível e se eleva (Mon âme mieux qu'au temps du tiède renouveau) Ouvrira largement ses ailes de corbeau), transformando em suas próprias exé-

\footnotetext{
${ }^{3}$ Baudelaire desreferencializa os componentes formadores das imagens naturais, criando, deste modo, um efeito de estranhamento disfórico e singularidade poética. Em printemps de boue, a imagem da estação primaveril, radiosa e ensolarada, vívida após o frio inverno, dá lugar a uma paisagem borrenta e enlameada. Assim como em l'autan froid, em que uma espécie de oximoro sensorial impõe-se pela mórbida transformação da própria natureza do vento sul (quente a frio).
} 
quias os componentes atmosféricos da natureza chuvosa e invernal (Et sur qui dès longtemps descendent les frimas, / O blafardes saisons), que passa a recobrir e dissipar a dor corpórea de uma existência atroz (Si ce n'est, par un soir sans lune, deux à deux,/ D'endormir la douleur sur un lit hasardeux.).

Lembremos, na leitura crítica de Brumes et pluies, da contribuição de Gaston Bachelard (1884-1962), filósofo e poeta francês que, em todas as suas obras, ressalta o poder de transformação das imagens quando postas por uma consciência perceptiva em contato com a materialidade do mundo exterior.

Bachelard declara que a imaginação não é a faculdade de formar imagens, mas de deformar as imagens fornecidas pela percepção, observando que, ao retirar as primeiras imagens do universo sensível, profundamente limitado, a imaginação carrega-as de intensidade afetiva e as liberta. Libertação compreendida como uma ação imaginante que modifica as formas originais de tais imagens, propondo combinações inesperadas, até aberrantes, entre elas, organizando, de imediato, a relação dessas, agora modificadas, com o mundo exterior. Segundo o filósofo, para quem a obra de Baudelaire sempre foi fonte profícua de reflexões, graças ao imaginário, a imaginação é inerentemente aberta, expansiva, mediadora da experiência da novidade no mundo psíquico: "imaginar é ausentar-se, é lançar-se a uma vida nova”, lembra Bachelard (1990, p. 3).

Por volta de 1910, diferentes artistas começaram a criar obras cujos estilos e maneirismos realizavam um nítido afastamento das referências do mundo objetivo (exterior), questionando com veemência valores estéticos da tradição acadêmica e de herança neoclássica. Depositárias das considerações estéticas de importantes pensadores do romantismo alemão, como Schiller, Friedrich Schlegel, e Immanuel Kant, teorias estéticas e espirituais ligadas às pesquisas artísticas desse período reforçavam entre os artistas o desejo de explicar e justificar as novas composições visuais, que pareciam desdobrarem-se em formas cada vez mais audaciosas. Aos 40 anos, Wassily Kandinsky pintaria Primeira Aquarela Abstrata, iniciando, com a evolução de suas composições em manchas de cor, justapostas a indefinidos traços e formas sobre um fundo claro, uma nova tendência na história da arte moderna, a chamada pintura abstrata.

Da arte abstrata, que terminantemente repudiava qualquer formalismo, gratuidade e decoração na composição das obras, surgiram artistas relevantes, cujos pensamentos estéticos pareciam revelar, conhecendo ou não, as mesmas preocupações de Kandinsky em relação à criação das formas visuais: considera- 
vam que o "que há de mais importante na forma é saber se resulta da necessidade interior ou não" (DICIONÁRIO DA PINTURA MODERNA, 1967, p. 14). Assim como Poe um século antes, um desses artistas, estando no Novo Mundo, pareceu enxergar o legado visual que viria de além-mar. Falamos do pintor americano Jackson Pollock (1912-1956), grande expoente do chamado expressionismo abstrato e já em vida equiparado aos mestres da arte moderna europeia.

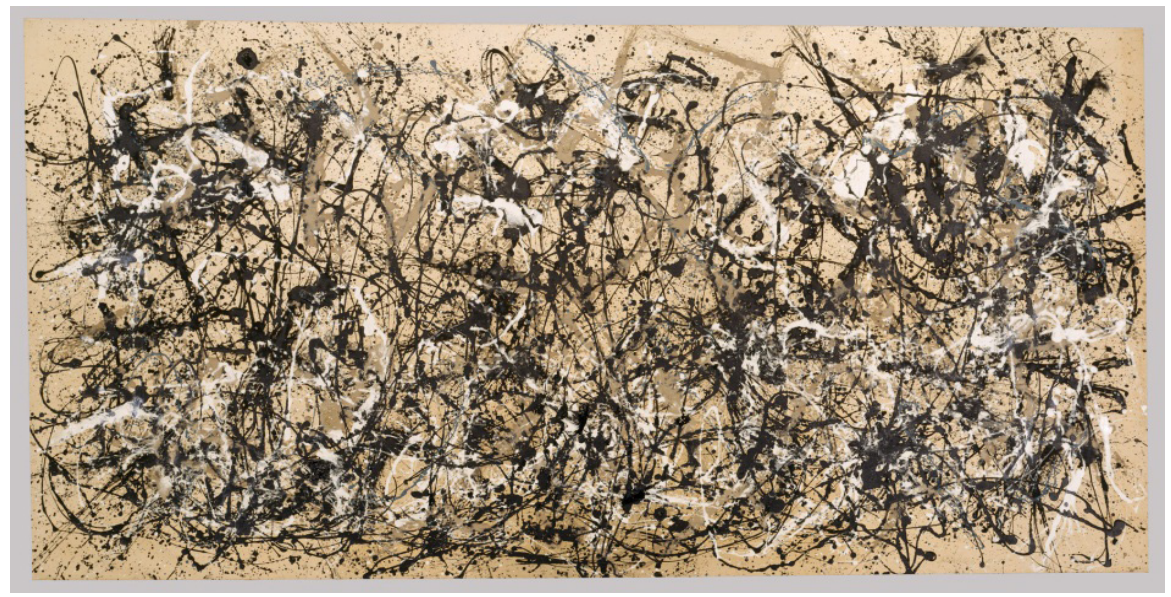

Fig. 2

Ao observarmos o quadro Autumn Rhythm (Number 30) (Fig. 2), de 1950, obra pertencente à fase abstrata do artista americano, encontramos, nas técnicas de composição e em seus significantes estruturais, profundas correspondências com o pensamento poético de Baudelaire, em particular, aqueles sintetizados nos versos de Brumes et pluies, analisados anteriormente. Serão, portanto, algumas dessas inter-relações estruturais entre a obra plástica de Pollock e o poema de Baudelaire que objetivamos demonstrar neste segundo e último movimento de nosso estudo.

Dizia Jackson Pollock, em relação à sua própria atividade criativa:

Minha pintura não provém do cavalete. Raramente acontece que estenda a tela antes de pintar. Prefiro aplicá-la contra a parede dura ou estendê-la no chão. Fico mais à vontade para trabalhar no chão. Sinto-me mais perto da pintura, dela fazendo parte de certo modo, porque posso passear em roda, trabalhar dos quatro lados e entrar literalmente dentro... Continuo a afastar-me cada vez mais dos utensílios usuais do pintor, como cavalete, paleta, brochas, etc., preferindo 
bastões, pás, facas, pintura fluida que deixo escorrer, pasta espessa com areia, vidro socado e outros materiais habitualmente estranhos à pintura. (DICIONÁRIO DA PINTURA MODERNA, 1967, p. 269)

As obras abstratas de Pollock, muitas vezes interpretadas como simples liberações das contingências, impõem-se, pelo contrário, como formas de rigoroso ofício e virtuoso domínio criativo. Para Pollock, a "pintura tinha vida própria, mas o produto final dependia sempre da vontade do artista." (FARTHING, 2009, p. 436).

Com Autumn Rhythm, três anos após a criação de seu primeiro dripping, ${ }^{4}$ Pollock realiza uma de suas mais poderosas composições abstratas utilizando tal técnica. A paisagem outonal figurativamente ausente, presentifica-se por meio de um vigoroso ritmo quase monocromático, que parece derramar sobre o saturado fundo marrom um emaranhado de manchas e linhas, "cuja espessura variável sugere diretamente o ritmo da duração" (DICIONÁRIO DA PINTURA MODERNA, 1967, p. 270). A superfície bidimensional do quadro torna-se, desta forma, espaço figural de uma experiência subjetiva e poética de temporalidade.

Considerando as mudanças dispostas pelo pensamento moderno às artes plásticas, os estudos acerca da experiência de temporalidade, desenvolvidos por Henri Bergson (1859-1941), mostram-se fundamentais à leitura comparativa a que nos propomos. Para o filósofo, o tempo, quando observado em seu caráter mais espiritual que material, determina-se como tempo psicológico ou "tempo vivido", equivalendo a uma sucessão de estados internos, imprecisos, que se interpenetram e amalgamam-se aos estados mutáveis da consciência, colocando-se irredutíveis em relação aos movimentos físicos que demarcam outro tempo, o tempo no mundo físico e exterior ao ser. Para Bergson, a ideia de duração interior pode ser compreendida como "duração pura", quando o sujeito experimenta uma sucessão de estados da consciência sem estabelecer uma separação entre o estado presente e os anteriores, e sim uma condição em que os estados anteriores prolongam-se e se interpenetram no estado presente:

${ }^{4}$ A técnica do dripping consiste "em pintar com caixas furadas por onde escorre a tinta" (DICIONÁRIO DA PINTURA MODERNA, 1967, p. 270). 
Quando sigo com os olhos, no mostrador de um relógio, o movimento da agulha que corresponde às oscilações do pêndulo, não meço a duração, como parece acreditar-se; limito-me a contar simultaneidades, o que é muito diferente. Fora de mim, no espaço, existe somente uma posição única da agulha e do pêndulo, porque das posições passadas nada fica. Dentro de mim, prossegue-se um processo de organização ou de penetração mútua dos fatos de consciência, que constitui a verdadeira duração. (BERGSON, 1988, p. 77)

Segundo Bergson, a duração manifesta-se como continuidade heterogênea e indivisível, destituída da condição imutável e imóvel dos momentos sucessivos que compõe o tempo espacializado, ou seja, o tempo mensurável. Para o filósofo, as percepções subjetivas, advindas de uma experiência interior de duração, penetram-se e ordenam-se entre si "como fazem as notas sucessivas de uma melodia" (BERGSON, 1988, p. 75), e deste modo, nos deixamos embalar por um contínuo de sensações, em que cada estímulo ou acréscimo de excitação organiza-se com as excitações precedentes, e seu conjunto, determinado não pela quantidade, mas por graus de intensidade, produz em nós "o efeito de uma frase musical que estaria sempre prestes a acabar e se modificaria, na sua totalidade, pela adição de alguma nota nova." (ibid., p. 76).

Realizando-se como uma melódica e intrincada composição de manchas e linhas, em Autumn Rhythm, deparamo-nos com dinâmicos fractais plásticos, que se diluem progressivamente à medida que a intensidade cromática do preto se espalha sobre a superfície, misturado por vezes ao branco. Tais fractais determinam vagas sensações visuais, que caracterizam um espaço-tempo frio e pesado, atravessado por sinuosidades de sublime leveza. A ausência de centro focal, ou qualquer ponto de fuga que estabeleça uma ordem de relevância entre as formas, faz com se imprima sobre a tela um continuum de estímulos visuais que, a partir da transfiguração dos constituintes formais plasmados sobre a superfície planar do quadro, nos faz imergir numa experiência subjetiva de duração, que se estabelece entre artista, sua obra (linguagem) e o observador, o qual, em última instância, se põe por meio da atividade interpretativa, numa contínua e simultânea recomposição de formas e sentidos, sensíveis e abstratos, dispondo-os no interior de um tempo simultaneamente poético e subjetivo, posto que o sujeito encontra-se imerso na e pela obra. 
Brumes et pluies e Autumn Rhythm correspondem-se, não pelo tema análogo que apresentam, mas sobretudo pela modulação rítmica e plástica realizada por ambos os sistemas de linguagem (verbal e visual), compondo imagens fractais de um tema comum aos dois artistas, a paisagem outonal. Por meio de tais procedimentos, distintos entre si, e que passam a se inter-relacionarem estruturalmente, produzindo significações poéticas correspondentes, pudemos, por fim, destacar nesta invariante, a composição de fractais poéticos, presente tanto na poesia de Baudelaire quanto nas pinturas abstratas de Wassily Kandinsky e Jackson Pollock, uma dupla iluminação das obras, juntamente com as teorias do imaginário de Gaston Bachelard e com as reflexões de Henri Bergson sobre o fenômeno de duração.

Cônscios da brevidade deste estudo, não pretendemos que tais considerações façam totalmente averiguadas as significações de uma poética tão complexa e substanciosa como a de Charles Baudelaire, nem mesmo conceitue a estética plástica dos dois artistas relacionados. O exercício comparativo, como o apresentamos na introdução deste trabalho, deteve-se apenas na apresentação de algumas similaridades estruturais entre as obras escolhidas, e a partir delas chegamos às invariantes, os fractais poéticos, determinantes das fecundas analogias que permearam todo esse estudo comparativo.

\section{Referências}

BACHELARD, Gaston. $O$ ar e os sonhos: ensaio sobre a imaginação do movimento. trad. de A. de Padua Danesi. São Paulo: Martins Fontes, 1990.

BAUDELAIRE, Charles. As flores do mal. trad. Ivan Junqueira. Rio de Janeiro: Nova Fronteira, 2012.

BENJAMIN, Walter. Origem do drama barroco alemão. trad. João Barrento. Lisboa: Assírio \& Alvim, 2004.

BERGSON, Henri. A evolução criadora. trad. B. P. Neto. São Paulo: Martins Fontes, 2005. BERGSON, Henri. Matéria e memória: ensaio sobre a relação do corpo com o espírito. 2. ed. trad. P. Neves. São Paulo: Martins Fontes, 1999.

DICIONÁRIO DA PINTURA MODERNA. Trad. Jacy Monteiro. São Paulo: Edimax, 1967.

FARTHING, Stephen. 501 grandes artistas. trad. Marcelo Mendes e Paulo Polzonoff Jr. Rio de Janeiro: Sextante, 2009. 
GARCIA-BERMEJO, J. M. Wassily Kandinsky. trad. Berta Rodrigues Silveira. Rio de Janeiro: Civilização Brasileira, 1995.

GONÇALVES, A. J. Laokoon revisitado; relações homológicas entre texto e imagem. São Paulo: EdUSP, 1994.

HOUAISS, Antonio. (Ed.). Dicionário eletrônico Houaiss da língua portuguesa. [S.I.]: Objetiva, 2009. CD-ROM.

KANDINSKY, Wassily. Do espiritual na arte. trad. M. H. de Freitas. Lisboa: D. Quixote, 1991.

KELLER, Hermann. Thoroughbass method: with excerpts from the theoretical works of praetorius, Niedt, Telemann, Mattheson, Heinichen, J.S. and C.P.E. Bach, Quantz, and Pad. Hermann Keller NY, 1959.

KLEE, Paul. Teoria del arte moderno. trad. Hugo Acevedo. Buenos Aires: Ediciones Caldén, 1979.

VICO, Giambattista. Princípios de uma ciência nova: acerca da natureza comum das nações. trad., sel. e notas de A. L. de Almeida Prado. Os Pensadores, 2. ed. São Paulo: Abril Cultural, 1979.

\section{Imagens}

Figura 1. Studie zu Winter II (1910), Wassily Kandinsky, óleo sobre cartão, 33 x 44,7 cm. Städtische Galerie, Munique, Alemanha. <https://www.artgalerie-bildershop.de/ item/images/1071816/800x800/277-01484-15-0.jpg>

Figura 2. Autumn Rhythm (Number 30) [1950], Jackson Pollock, esmalte sobre tela, 266.7 x $525.8 \mathrm{~cm}$. Metropolitan Museum of Art, Nova York, EUA. ,<http://www.metmuseum.org/toah/images/hb/hb 57.92.jpg> 